\section{Historical Archaeology in the Next Decades: An Introduction}

In anticipation of the upcoming 50th anniversary of the founding of the Society for Historical Archaeology (SHA), I was interested in putting together a collection of articles on the state of the discipline that would give a sense of where it is heading. The last 50 years have seen tremendous growth in historical archaeology as it blossomed from a small group of "historic sites" researchers into a vibrant field that explores broad and important questions about the meaning of material life in modernity worldwide. The field has grown in stature and scope, with important contributions to archaeological and anthropological theory and method being a routine result. Historical archaeologists have offered major contributions to questions regarding the meaning and practice of race, gender, sexuality, labor, agency, colonialism, capitalism, materiality, corporeality, globalization, community-based research, and more. The complicated cultural, political, and economic engagements involved in constructing the modern condition require archaeological contributions in order to shed light on those people and relationships not documented or considered significant, and to understand the rich interconnections between people, places, and things that created the present globalized world.

To follow through on these interests I solicited proposals from a range of "mid-career" researchers for articles on areas in which they think historical archaeology will grow in the next decades. I was looking for authors with enough experience to understand the way research trends develop, as well as those who are in a position to bring their visions to fruition, at least in part! I was thrilled to see so much interest in this collection and extremely happy with the large number of great paper proposals submitted. In the end, I selected articles to appear in this issue based on how they illustrate several complementary ways of envisioning the future, and for how they would work together to demonstrate the vitality and potential of historical archaeology. Some of those originally involved were not able to continue and, therefore, some key topics and regions are missing, such as gender, research in and on Africa, and small finds, such as clothing and adornment. Nevertheless, this collection does offer new material that provides breadth and depth regarding the future of the discipline in the areas of publication, technology, intercultural relations, and globalization, as well as how these themes can be explored and given greater clarity through the process of archaeological research.

\section{Motion and Networks}

I briefly highlight here two main themes shared by many of these articles: motion and networks. The collection starts with $\mathrm{J}$. W. Joseph's personal and professional reflections written through the lens of the Bakongo dikenga, a material symbol found on artifacts in the African diaspora, that represents a African cosmogram. A past editor of Historical Archaeology and current president of the SHA, Joseph uses the form of the dikenga to network the past and future of historical archaeology and to tie these to the networks that created and bind the African diaspora, a community largely defined by movement. These are then tied in with professional archaeological practice via discussions of cultural resource management and publications. Joseph masterfully finds ways for the dikenga to stand for the field, even as he guides us as historical archaeologists to reflect on the role of our own experiences in the making of our work.

Edward González-Tennant shifts the discussion to a key component of the future: technology, specifically the use of geographical information systems (GIS) technology in archaeological research, dissemination, and community engagement. In a basic way, 
GIS research is driven by a desire to make spatial networks of sites and data visible. Whether using GIS for predictive, least-cost, or other research purposes, the technology allows researchers to identify relationships visible only when data are interconnected. González-Tennant expands from a discussion of research applications to explore ways that GIS can support community engagement. Discussing participatory GIS, counter-mapping, and video game-based immersive GIS, the article explores a range of powerful examples for public access to and use of archaeological knowledge. González-Tennant thus explains the vital task archaeologists should undertake to build meaningful networks between professionals and publics not only to meet the burden of dissemination, but also open spaces and means for ongoing dialogue.

Lynette Russell calls for a great rapprochement between archaeology and history, or what she calls "History with a capital $H$." By this she refers to a more inclusive archaeological practice that seeks to overcome the arbitrary boundaries that emerged with settler colonialism, most notably between indigenous and colonial peoples, cultures, and histories. The impact of this colonial mindset is made most evident in the analysis of sites associated with early intercultural contact, where the very categories we archaeologists use were, at best, in flux. She makes the excellent point that when we consider the moment of encounter, the content and structure of the frontier was always a very local phenomenon that can and must vary from site to site. The result is a sense that the networks we use to construct meaning in the past were, themselves, always hybrid and in a state of becoming.

Kurt Jordan examines a research area similar to Russell in his article on "Categories in Motion." Like Russell, he calls for us as archaeologists to reexamine the way we frame our subjects. He suggests the use of theories of holism and vantage point as ways that avoid essentialist and static frames, such as colonizer/colonized, in our approach to the past people we study. With holism, archaeologists approach materials as evidence of the complex and integrated fields of interaction, which themselves were in flux, even as they determined the nature of those involved.
Theories of vantage point call for us to see that events and relations are engaged and understood in multiple specific ways. There are no single "indigenous" or "colonial" perspectives, rather these are diverse and formed as the result of specific historical patterns that themselves are also in motion. Jordan carries his discussion further in a consideration of the social practice of archaeology, where he makes a strong case for more thinking and action in the way community collaborations, especially indigenous ones, are conceived and carried out. A notable observation is that archaeologists seem to have adopted a sense that dirt archaeology and community engagements are separate activities, a process that Jordan worries perpetuates the marginalization of indigenous people from the making of archaeological knowledge. Rethinking how these networks, in particular, are built should be a key part of our future.

LouAnn Wurst and Steve Mrozowski also examine archaeological categories in their article on "Capitalism in Motion." In this study, they call for a deeper archaeological study of the way capital, capitalists, and commodities-key aspects of any study in historical archaeology-are themselves artifacts that move through space and time. Drawing specifically from Bertell Ollman, they demonstrate how capitalism is inherently dynamic, as the relationship between capital and labor is always in negotiation and in flux, and that the competition that drives the system will move wealth, work, and resources across historical landscapes. To illustrate these points, the authors consider the creation of the industrial community at Lowell, Massachusetts, and a fascinating examination of the history of coal, a material endemic to a wide range of historical archaeological sites.

The next group of articles considers questions related to the internationalization of historical archaeology. While, in 2017, the SHA remains dominated by North American practitioners, there is no doubt that the field and the organization will continue to add more international research and, thus, requires some consideration of theory related to this expansion. Pedro Funari and Lúcio Ferreira contribute thoughts on the practice of historical archaeology from a Latin American 
perspective. They emphasize that the expansion of historical archaeology brings with it North American-based WASP perspectives that do not work in the effort to understand history and culture in Latin America and other developing sections of the world. They call for a more nuanced approach that recognizes the diverse histories, interests, and power of peripheral nations and localities, especially as these nations move into positions of greater global power. In fact, they offer a counterpoint to Wurst and Mrozowski by calling for downplaying research on capitalism, which they see as homogenizing, in favor of examinations of cultural difference, such as between Spanish and Portuguese perspectives on Latin America or between colonist planters and maroon communities.

Audrey Horning also explores developments related to the creation of networked global historical archaeologies. She employs a pragmatist standpoint and begins with a comparison of the traditions in historical archaeology in America and the British Isles, illustrating strengths and weaknesses in each, while also recognizing that there is usefulness in this diversity. She also considers the emergence of new shared interests in the U.S. and Europe in the archaeologies of colonialism and capitalism; however, she again emphasizes the presence and value of diversity in this research. To demonstrate, she reviews emergent historical archaeologies in India, Japan, Iran, and in territories of the former Ottoman Empire. Producing more than a survey, Horning is calling for an appreciation of the complexities that define the way national traditions and interests color historical archaeology in postcolonial settings. She also offers an extensive review of her own public archaeology work with the Corrymeela Community in Northern Ireland, which involves addressing a wide array of religious, national, and cultural interests, while also "challeng[ing] blanket assumptions about Ireland's current postcoloniality and provid[ing] a space within which to complicate overly prescriptive understandings of colonial entanglements."

Eleanor Casella offers another take on globalization, though from a more phenomenological perspective of "being global." She draws from relational theory to demonstrate that archaeological sites, as combinations of moments, actions, spaces, and ideas, form what Tim Ingold calls meshworks. These are the knots of entanglement that form when complex interactions surface via topology rather than topography. Casella explains the difference between these as one in which the presumed material spatial aspects of a topographic rendering are renegotiated through the relational topological processes that create, rather than document, space, especially through the fluidity of movement, intersection, and power. This perspective allows Casella to reinterpret even prison spaces in Australia and Tasmania less as stable and enclosed sites of confinement than as sites in "constant biography or motion" as they are embedded in global flows of ideas, people, and commodities.

\section{Historical Archaeology and Time}

The final articles in the collection examine questions essential to the relationship between archaeology and periodization, especially given the complexities of "modernity" and the emergence of the field of contemporary archaeology. Alfredo González-Ruibal focuses specifically on the "time of modernity" in an effort to problematize the way time is understood and deployed in archaeological research. He criticizes the tendency of historical and postmedieval archaeology to be subservient to the periods and temporal frameworks produced by historians. He offers three counterpoints to help to relieve this dependence. He first explores the "time of things" as a way to center the materiality of objects in time that flow at varied rates, or not at all, as traditions are incidentally preserved. Second, he considers multi-temporality, which counters the singular linearity in the theory and practice of time in modernity. Citing multiple examples of the conflict between the experience of supermodernity and other ways of living at the same moment, González-Ruibal illustrates that time itself can be in conflict or, more specifically, that "time is seldom a simple vector." González-Ruibal also discusses the time of ethics in a review of several ways that archaeology itself counters efforts to annihilate time. In the excavation 
and recovery, for example, of mass graves from the Spanish Civil War or through open engagement with ongoing injustices, such as the marginalization of Native Americans, archaeology reminds the present that the past was only buried, not destroyed. As he says: "The time of archaeology, then, has to make room for ghosts."

Rodney Harrison's article examines some the key foundations of the recently organized field of contemporary archaeology. He argues that Anglophone historical archaeology has much in common with contemporary archaeology, and that the two fields would benefit from greater integration. He is also less interested in the future of these archaeological fields and their relationships than in the way both conceptualize and, as important, create futures. Harrison sees archaeology as an intervention in the present that conceives not only the past, but also futures where those pasts will live. As he states:

[I]f it is argued that archaeology brings its own distinctive "sensibility" to its topic of study ... then it follows that archaeology might also provide a particular lens with which to shed light on the future or, indeed, through its engagement with the presents in which the future is made, on multiple possible futures.

To elaborate, Harrison describes various aspects of the way the heritage domain is inherently future oriented. His current collaboration, Heritage Futures, employs ethnography, archaeological ethnography, and ethnoarchaeology, among other methods, to critically examine heritage practice across a range of interests, including archaeology and preservation, as well as nuclear-waste disposal and seed banks. He concludes that "the 'future' of historical archaeology lies precisely in what has traditionally been an area of strength-a strong multi-source approach," while also calling for a deeper analysis and understanding of contemporary archaeological practices and materialities, aspects of research that also draw on historical archaeology's traditional strengths.

This thematic issue includes a diverse series of forward-looking statements and ideas that provide a sense of where historical archaeology is headed. Of course, the collection is not all-encompassing, and many other futures may also arise. However, I think most possibilities will share some of the key attributes presented here, especially as historical archaeologists engage and unpack the dense complexities of past and present modernities, and the rich human experiences that produced the historical archaeological record of the modern and contemporary eras.

\section{Acknowledgments}

I am most grateful to the contributing authors in this collection. The process of putting this thematic issue together has been a mutual effort of thoughtful writing, review, and revision. Plus, the authors were absolutely wonderful about staying on schedule! I also want to thank the many outside readers who contributed their time and insights to these papers. These include Carol McDavid, Margie Purser, Diana Loren, Nan Rothschild, Juan Martin, Matthew Johnson, Robert Paynter, Gavin Lucas, Mark Leone, Natascha Mehler, Sarah Croucher, and Paul Mullins. 